\title{
Exploring the links between drug use and sexual vulnerability among young female injecting drug users in Manipur
}

Archana Oinam

Follow this and additional works at: https://knowledgecommons.popcouncil.org/departments_sbsr-rh

Part of the Demography, Population, and Ecology Commons, Family, Life Course, and Society Commons, International Public Health Commons, Substance Abuse and Addiction Commons, and the Women's Health Commons

How does access to this work benefit you? Let us know!

\section{Recommended Citation}

Oinam, Archana. 2008. "Exploring the links between drug use and sexual vulnerability among young female injecting drug users in Manipur," Health and Population Innovation Fellowship Programme Working Paper no. 6. New Delhi: Population Council. 
This report is the result of a project entitled "Exploring the Links between Drug Use and Sexual Risk Practices among Young Female Injecting Drug Users in Manipur," undertaken as part of the Health and Population Innovation Fellowship (HPIF) awarded to the author in 2005.

The HPIF programme is administered by the Population Council, New Delhi and is a continuation of the MacArthur Foundation's Fund for Leadership Development (FLD) fellowship programme that continued over the period 1995 to 2004. The Council is grateful to the MacArthur Foundation for its support to this programme.

The HPIF programme aims to support mid-career individuals who have innovative ideas, leadership potential, and the capacity to help shape policy and public debate in the field of population, reproductive health and rights in general, with a focus on two priority themes maternal mortality and morbidity, and the sexual and reproductive health and rights of young people. Since the transfer of the programme to the Population Council through 2006, a total of 17 individuals have been supported under the HPIF programme.

\section{For additional copies of this report, please contact:}

Archana Oinam

Sega Road Takhel Leikai

Near City School

Imphal 795001, Manipur

Email: archoinam@rediffmail.com
Population Council

Zone 5A, Ground Floor

India Habitat Centre,

Lodi Road, New Delhi 110003

Phone: 011-2464 2901/02

Email: info-india@popcouncil.org

Web site: http://www.popcouncil.org/asia/india.html

The Population Council is an international, non-profit, non-governmental organisation that seeks to improve the well-being and reproductive health of current and future generations around the world and to help achieve a humane, equitable and sustainable balance between people and resources. The Council conducts biomedical, social science and public health research, and helps build research capacities in developing countries.

\section{Copyright C 2008 Archana Oinam}

About the author: Archana Oinam has a MA in Psychology and a B.Ed. She has been working, since 1999, on matters relating to HIV prevention and care. Most recently, she has been Project Manager, Social Awareness Service Organisation (SASO), Imphal, where her focus has been on HIV/AIDS prevention, care and support, including among intravenous drug users.

Suggested citation: A. Oinam. 2008. "Exploring the Links between Drug Use and Sexual Vulnerability among Young Female Injecting Drug Users in Manipur," Health and Population Innovation Fellowship Programme Working Paper, No. 6. New Delhi: Population Council.

\section{(P) Population Council}




\section{Exploring the Links between Drug Use and Sexual Vulnerability among Young Female Injecting Drug Users in Manipur}

Archana Oinam

Fellow

Health and Population Innovation Fellowship Programme 


\section{Contents}

List of figures and tables __ iv

Introduction

Background __ 3

Study design _ 5

Ethical concerns _ـ 7

Limitations $\quad 7$

Profile of the study participants __ 8

Respondents' relations with parents _ 11

Respondents' family situation in childhood __ 11

Interaction with parents 12

Experiences and patterns of drug use _ـ 14

Initiation of drug use __ 14

Patterns of drug use 15

Unsafe injecting practices _ـ 17

Supporting the drug habit__ 18

Support mechanisms 20

Sexual behaviour of injecting drug users _ 21

Sexual experiences with boyfriends _ 21

Sexual experiences with other partners _ 22

Health status and service seeking behaviour _ 25

Health status 25

Service seeking behaviour _ 26

Factors underlying female injecting drug users' vulnerability to HIV __ 29

Limited self-perception of HIV risk _ 29

Limited in-depth awareness of safe sex and drug use behaviours __ 29

Traditional attitudes towards sexuality and gender roles__ 31

Summing up and recommendations _ـ 32

Summing up _ـ 32

Recommendations__ 32

References _ 35

Acknowledgements __ 37 


\section{List of Tables and Figures}

Table 1: Socio-demographic profile of respondents 9

Table 2: Parents' survival/co-residence status and family's economic status when respondent was growing up

Table 3: Interaction with parents, perceptions of parental attitudes and communication with parents on various topics 12

Table 4: Initiation of drug use 15

Table 5: Patterns of drug use 16

Table 6: Drug injecting practices and reasons for reusing injecting equipment 18

Table 7: Strategies adopted to support the drug habit 19

Table 8: Perceptions of the importance of parental, peer and societal reactions

Table 9: $\quad$ Sexual experiences with boyfriends 21

Table 10: Respondents' sexual experiences

Table 11: Health problems experienced in the three months prior to the survey

Table 12: Injecting drug users' care seeking behaviour and satisfaction with quality of care received at facilities

Table 13: Priority needs of injecting drug users, as reported by respondents 28

Table 14: Respondents' perception of risk and experience of HIV testing 29

Table 15: Awareness of reproductive health matters and safe sex behaviours 30

Table 16: Awareness of risky drug use practices 31

Table 17: Respondents' attitudes to sexuality and drug use 31

Map 1: Manipur state and the study sites 6 iv $\mid$ Archana Oinam 


\section{Introduction}

The transmission of HIV through injecting drug users is substantial; indeed, estimates indicate that 5-10 percent of all new HIV infections worldwide result from the use of contaminated equipment by injecting drug users (WHO/UNAIDS/UNODC, 2004). Injecting drug users are a critical bridge population in the transmission of HIV/AIDS because of their vulnerability to dual risk factors, namely, unhygienic injecting drug use and unsafe sexual behaviours, including multiple partner sex and infrequent condom use (Anderson and Hua, 1998; Eicher et al., 2000; Kumar, 2000; Liu et al., 2002; McEwan, McCallum and Madnock, 1992; Panda et al., 2000; 2001; Sahai Trust and Population Council, 2004a; 2004b; Sarkar, Mukherjee and Roy, 1991; Sharma et al., 2003).

The transmission of HIV through injecting drug users is recognised as a major problem in many areas in India, in particular in the north-eastern region, including the state of Manipur. Indeed, Manipur is one of the six high HIV prevalence states in the country, with 1.25 percent of antenatal women testing positive for HIV in 2005 (NACO, 2006). Manipur also reports one of the highest HIV sero-prevalence rates among injecting drug users in the world; recent data from the sentinel surveillance survey indicate that HIV prevalence among injecting drug users in Manipur is 46.8 percent (MSACS, 2006).

Although female injecting drug users may constitute only a small proportion of the injecting drug user population, studies suggest that they too play a critical role in the spread of the HIV epidemic both through unsafe injecting practices as well as through sexual risk taking; however, there may be a greater likelihood of female injecting drug users acquiring HIV through the sexual route than through the use of contaminated injecting equipment (Strathdee et al., 2001). Evidence also suggests that female injecting drug users are likely to resort to paid sex or selling drugs as a source of income to support their drug using habit (Murthy, 2002); in turn, women who trade sex for money or drugs are more likely to share needles than female injecting drug users who do not engage in sex work (Allan, 1994).

Unfortunately, gender disaggregated data on injecting drug users are not available, and little is known about the extent to which female injecting drug users are at increased risk of HIV as a result of their sexual behaviour and unsafe drug using practices. Moreover, the few available studies have largely focused on men, and programmes generally do not attempt to reach and work with female drug users. One reason why female injecting drug users are likely to be under-represented in surveys and programmes is because women are more likely to be sensitive to the stigma associated with drug use and consequently are more likely to conceal their drug use than men (Amin and Burrows, in press; Hunter and Judd, 1998; Osimani, 2003).

Given the high prevalence of HIV in Manipur and the critical role that female injecting drug users play in the transmission of HIV infection, it is becoming increasingly important to understand the sexual behaviours and drug use experiences of this group. This report sheds light on the situation and experiences of female injecting drug users 
aged 15-34 in Manipur in relation to drug use and sexual behaviour. It describes the health status and patterns of treatment seeking of female injecting drug users. It also explores the factors underlying female injecting drug users' vulnerability to HIV, including limited in-depth awareness of safe sexual behaviours and drug use practices, and limited self-perception of HIV risk, and suggests recommendations to address their special vulnerabilities. 


\section{Background}

Manipur is a small state in north-eastern India, with a population of 2.3 million (RGI, 2001). The state has nine districts-Bishnupur, Chandel, Churachandpur, Imphal East, Imphal West, Senapati, Tamenglong Thoubal and Ukhrul. Five of these districts are in the hilly areas and are inhabited by 33 Scheduled Tribes listed in the Constitution of India including the Kabui, Thadou and Tangkhul; the four remaining districts are in the plains and are inhabited largely by the Meiteis, an ethnic group of Vaishanavite Hindus. While literacy rates are relatively high in Manipur $(71 \%, 80 \%$ and $61 \%$ for the total, male and female populations, respectively; RGI, 2001), the state remains poorly developed on other economic and social indicators, including poor industrial growth, limited employment opportunities and few facilities for higher education. As far as health facilities are concerned, the state has one regional teaching college, one state government hospital, five district hospitals, 16 community health centres, 72 primary health centres, 420 sub-centres and 20 medical dispensaries (healthmanipur.nic.in/health_institutions.html). Politically, the state has witnessed considerable ethnic violence, insurgency and unrest since the 1950s.

Manipur shares a $358 \mathrm{~km}$ long border with Myanmar on the east. The National Highway 39 leads directly to the "Golden Triangle," where an estimated 8-10 percent of the global production of opium takes place, from which the purest form of heroin is manufactured (UNODC, 2007). In 2004, it was estimated that Myanmar produced 370 metric tonnes of opium, second only to Afghanistan, the world's largest producer of opium. Myanmar is also considered one of the world's largest producers of amphetamine type substances (ATS), with the capacity to produce 700 million tablets a year. Recently developed laboratories are believed to be capable of producing up to 100,000 tablets per day, a three-fold increase in output from previous assessments. Proximity to Myanmar has made heroin and ATS relatively easily available in Manipur, which has increasingly become part of the international drug trafficking route (Devaney, Reid and Baldwin, 2006).

Extensive drug use has been observed in Manipur for over thirty years. In the 1970s, the popular drugs used were morphine, norphine and pethedine, which were used both orally and intravenously. Heroin, known locally as No. 4, became popular from the early 1980s and remains a commonly used substance along with Spasmo-proxyvon, an analgesic (Singh, 2001).

As noted, despite the relatively high use of drugs in Manipur as compared to other areas in the country, there are few studies of injecting drug users in the state. Evidence on female injecting drug users in the state is even more limited, and the few available studies on HIV and drug use among women in Manipur tend to focus on sex workers. While precise figures for injecting drug users in the state are not available, a rapid situational assessment conducted in 2000 suggests that there are 14,000 drug users in Imphal, the capital of Manipur, of whom 92 percent are injecting users (Singh, 2001). A national survey that explored drug use and related behaviours indicates that a larger proportion of 
drug users in Manipur reported relations with sex workers in the 12 months preceding the survey (2001) as compared to India nationally (23\% vs 16\%) (NACO, 2002). Among injecting drug users in Manipur specifically, more than half (55\%) had shared syringes and needles when injecting the last time, and only 34 percent and 14 percent respectively had used condoms consistently with sex workers and regular sexual partners (NACO, 2002). Evidence on female drug users in Manipur can be drawn from a study of sex workers in the state. Findings show that of a sample of 69 sex workers, 39 injected drugs; and 22 of the 39 injecting drug users were HIV-positive compared to six women who did not inject drugs. Moreover, of the 36 women who consented to a vaginal examination, 29 had abnormal vaginal discharge, suggesting the prevalence of unprotected sex (Panda et al., 2001).

Only a few programmes in Manipur specifically focus on the needs of female injecting drug users. Of the 21 Government-funded drug rehabilitation centres in Manipur, for example, only three have services for female drug users; even so, women find it difficult to access services at these centres. NGO programmes, similarly, focus on males. For example, most of the $46 \mathrm{NGOs}$ that have undertaken programmes in partnership with the Manipur State AIDS Control Society to ensure safe drug use and prevent the transmission of HIV among injecting drug users focus on male injecting drug users. ${ }^{1}$ Moreover, female injecting drug users tend to be served for the most part only through programmes designed for sex workers; for example, the NGO Meitei Leimarol Sinnai Sangh (MLSS) in Imphal serves 1,200 sex workers, of whom 160 have been identified as injecting drug users (personal communication, MLSS Secretary).

Evidence from these programmes suggest an increase in the number of female injecting drug users in the state and a significant relapse rate. Evidence from NGOs also points to the fact that female injecting drug users resort to sex work to finance their drug habit, and that paid sex may be riskier for injecting drug users than for other sex workers.

Moreover, sex workers who are injecting drug users are not only more likely to engage in sex with more clients than other sex workers, but are also more likely to engage in sex without condoms and to experience violence perpetrated by their clients (SASO, 2004).

1 A few NGOs, such as the Centre for Social Development and the Social Awareness Service Organisation (SASO), specifically address the needs of female injecting drug users. 


\section{Study design}

The study was conducted in Imphal East and Imphal West in Manipur state. In view of the fact that female injecting drug users are a group that lacks visibility and the paucity of evidence on their lives and vulnerabilities, the study was designed to include a number of qualitative methods as well as a survey.

The first phase of study was intended to gather information on the context in which drug use takes place and the terminologies used by injecting drug users to describe their drug use and sexual experiences. A mapping exercise was undertaken in the districts of Imphal East and Imphal West with the help of injecting drug users and service providers to identify places where injecting drug users gathered. In the process, researchers were able to observe the injecting practices of women, including the extent to which they shared needles, syringes and other injecting equipment/material, and the ways in which they prepared syringes and injected themselves. The mapping process also helped to identify the places from where injecting drug users procured injecting materials (such as syringes, condoms and medi-swabs). Next, six focus group discussions (three each in Imphal East and Imphal West) were conducted with groups of eight to 10 female injecting drug users to explore and understand the terminologies they used, and their perceptions, knowledge, behaviours and attitudes. Information derived from this phase of the study was then used to inform and design the survey instrument and in-depth interview guidelines.

In the second phase, a survey of female injecting drug users was conducted. Given the lack of visibility of this group, a snowball sampling technique was used. Although the study focused on Imphal East and Imphal West, the snowball sampling method enabled researchers to locate injecting drug users in other districts, and they were invited to participate in the study. All participants were identified through peer-based and outreach workers who were already involved in intervention programmes for injecting drug users in the area.

A total of 218 female injecting drug users were identified, of whom 200 consented to participate in the survey. A total of 120 injecting drug users were interviewed in Imphal East and Imphal West, 62 from Churachandpur district, 12 from Chandel district and two each from Senapati, Bishenpur and Ukhrul districts (see Map 1). The survey instrument drew on several existing questionnaires and was finalised keeping in mind the importance of asking questions in a non-threatening, non-judgemental and ethically sound manner.

The questionnaire was translated from English to Manipuri, and was field-tested prior to finalisation. The survey was conducted during April-August 2006.

In the third phase, a total of 20 respondents from the survey were interviewed in depth to probe their experiences of drug use and sexual practices. 


\section{Map 1:}

Manipur state and the study sites
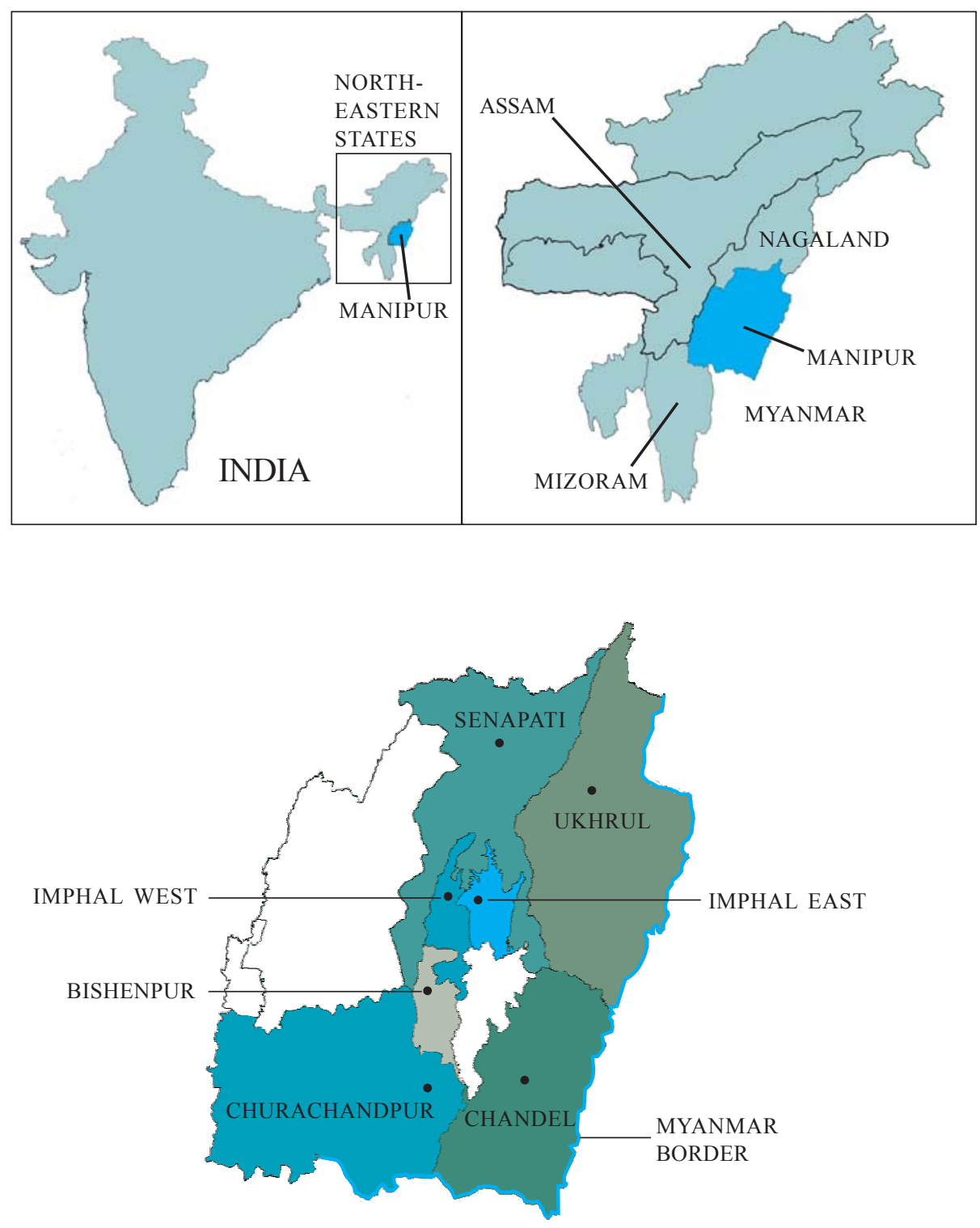

Source: Adapted from www.mapsofindia.com.

Note: Map not drawn to scale. 
Finally, interviews were conducted with a total of 10 key informants: five service providers for sexually transmitted infection (STI), including three from the NGO sector, one police official, two policy makers and two pimps. $^{2}$

\section{Ethical concerns}

In the absence of a local social science research ethics committee, the study team formed an ethical committee comprising eight members, including researchers, academicians, an advocate, leaders of community-based organisations and experts in the field of drugs and HIV/AIDS. The committee met regularly during the study period and guided the team on ethical issues.

Measures to ensure anonymity and confidentiality were strictly observed. A two-stage consent procedure was adopted in recruiting study participants. In the first stage, potential study participants were approached by a peer or known service provider who informed them about the study and sought their oral consent to participate; if consent was provided, the individual was approached by a member of the study team who explained more fully the objectives of the study and obtained formal consent.

After data were collected, the anonymity and confidentiality of study participants continued to be maintained. Completed questionnaires were stored in a secure place and were accessible only to the study team. A unique identification code was used for each study participant, and the link between her name and the identification code was kept separately. In-depth interviews were tape-recorded only if the study participant consented. All study participants were assured that non-participation would not in any way affect their access to health care. No cash remuneration was provided to the participants; however, food and refreshments were offered after the interview.

\section{Limitations}

We acknowledge that as the sample was drawn through snowball sampling, findings may not be representative of all female injecting drug users in the Imphal area, but rather, only those who were approached and consented to being interviewed. Moreover, as a result of the two-tiered consent-taking procedure, the characteristics of those who did not consent to participate when approached by peers or health care providers could not be assessed. The particular groups most likely to have been missed are those who use drugs most clandestinely and those who do not seek services from NGOs; for example, college students who obtain their supply of drugs through other users, such as their male partners. The team tried to approach some of these difficult-to-reach female injecting drug users through their male partners, but most of this group refused to participate in the study. Others who refused to participate include those who demanded to be paid for granting an interview. It is, therefore, acknowledged that study findings are likely to be biased towards those who were more open about their drug use.

2 A pimp is a man who finds customers for prostitutes. 


\section{Profile of the study participants}

As can be seen from Table 1, two in five respondents were aged 25-29 and their mean age was 27 years. As in Manipur more generally, the majority of respondents (85\%) were Christian. Almost all the tribes residing in Manipur were represented in the sample, suggesting that injecting drug use is not confined to particular tribes in the state.

Injecting drug users appeared to be relatively disadvantaged socio-economically. For example, their educational attainment levels were poor: 12 percent had never been to school and 20 percent had completed five or fewer years of schooling. Only a few had stable employment - almost three in five (59\%) were not working at the time of the survey and only a small minority of those who were working were employed in salaried jobs. The majority were engaged in small and petty businesses, earning Rs 2,000-3,000 per month.

The vast majority of injecting drug users in the study were intra-district or inter-district migrants. For example, 108 of the 120 respondents in Imphal were from other areas of the state, and 60 of the 62 respondents in Churachandpur town were from the same district; several of the remaining 18 interviewed in their home districts also reported residing in Imphal at some point of time. Many injecting drug users did not have a permanent residence; while about half reported current residence with their family, many reported that they alternated between residing with the family and friends in rented accommodation in the town. Many perceived this accommodation as temporary and returned to their areas of origin from time to time. Finally, their marital status distribution indicates their unstable lives. As many as one-third were divorced or separated and 12 percent were widowed-proportions very likely to be different from those reported for the general population of women aged 15-25 in Manipur.

Most respondents (88\%) had consumed alcohol; and just over half of all respondents (55\%) reported that they had initiated alcohol consumption by 20 years. Regular consumption of alcohol was reported by almost a quarter (23\%) of the women (not shown in tabular form). 


\section{Table 1:}

Socio-demographic profile of respondents $(\mathrm{N}=\mathbf{2 0 0})$

\begin{tabular}{|c|c|}
\hline Characteristic & $\%$ aged: \\
\hline 15- 19 & 5.0 \\
\hline $20-24$ & 21.5 \\
\hline $25-29$ & 40.0 \\
\hline $30-34$ & 33.5 \\
\hline Mean age & 27.0 \\
\hline Religion & $(\%)$ \\
\hline Christian & 84.5 \\
\hline Hindu $^{1}$ & 12.5 \\
\hline Muslim & 3.0 \\
\hline Ethnic group/Scheduled tribe & (\%) \\
\hline Kuki & 23.5 \\
\hline Paite & 13.0 \\
\hline Zou & 11.0 \\
\hline Tangkhul & 10.0 \\
\hline Mizo & 8.5 \\
\hline Anal & 5.5 \\
\hline Hmar & 4.0 \\
\hline Others $^{2}$ & 13.0 \\
\hline Education & (\%) \\
\hline Never attended school & 12.0 \\
\hline Class $1-5$ & 19.5 \\
\hline Class $6-10$ & 45.5 \\
\hline Class $11-12$ & 17.5 \\
\hline Graduation and above & 6.0 \\
\hline Employment status & (\%) \\
\hline Self-employed & 21.0 \\
\hline Daily wage & 11.0 \\
\hline Salaried (private or government) & 9.5 \\
\hline Unemployed & 58.5 \\
\hline
\end{tabular}




\begin{tabular}{l|r}
\hline Average monthly income, of those employed $(\mathbf{N}=\mathbf{8 3})$ & $\mathbf{( \% )}$ \\
\hline Rs. 500 & 1.2 \\
Rs. $501-1,000$ & 13.3 \\
Rs. $1,001-2,000$ & 26.5 \\
Rs. 2,001-3,000 & 44.6 \\
>Rs. 3,001 & 14.5 \\
\hline Current residence & $\mathbf{( \% )}$ \\
\hline With family & 46.0 \\
With friends & 30.0 \\
With husband/boyfriend & 19.0 \\
Alone & 3.0 \\
Care home & 2.0 \\
\hline Marital status & $\mathbf{( \% )}$ \\
Single & 29.0 \\
Currently married & 25.0 \\
Separated/divorced & 34.5 \\
Widowed & 11.5
\end{tabular}

1 Includes $11.5 \%$ who are Meitei.

2 Includes the following ethnic groups/tribes: Baite, Chin Zou Mi, Gangte, Kabui, Maring, Meitei Pangal, Semte, Thadou, Vaiphei and Zew. 
Most respondents' families had been affected by the limited economic opportunities and political instability in the state. As can be seen from Table 2, over a quarter of respondents $(27 \%)$ were from poor families; that is, they did not have a regular source of income and did not own any land. Indeed, as described in the narratives, several families had to resort to selling alcohol and engaging in sex work as a means of earning money.

Many families were displaced as a result of ethnic strife. For example, respondents describe clashes in 1996-97 that resulted in their homes in the interior villages being burnt and families having to migrate to towns, including Imphal, in search of livelihoods, which may have played a role in fostering drug dependence among women. The following quote is illustrative:

My parents sent my elder brother and sister to Imphal [after the clashes]. I was very young so I stayed behind with my parents in Churachandpur. To support the family, my parents started selling alcohol. I helped them sell alcohol. I used to attend school in the village but after we shifted to Churachandpur town, I was not admitted in school. I started drinking and taking pills [drugs] with friends. That was our way of enjoying ourselves and having fun. (22 years, female injecting drug user,

Churachandpur district)

\section{Interaction with parents}

Respondents were asked to describe their interaction with parents, their perceptions of parental attitudes, and their level of communication with parents on various topics. As seen in Table 3, over three-quarters (78\%) reported serious conflict with family members, and three-fifths (61\% and $64 \%$, respectively) reported that their parents did not understand their needs or did not spend enough time with them. More than half of all respondents $(54 \%)$ had been beaten by one or both parents while growing up. About half reported that their parents were very strict, particularly on such matters as how money was spent and to a lesser extent, on their choice of friends. Further, while all respondents perceived that their parents would disapprove of drug use, less than half (42\%) felt that their parents would disapprove of them having male friends or boyfriends.

\section{Table 3:}

Interaction with parents, perceptions of parental attitudes and communication with parents on various topics $(\mathrm{N}=200)$

\begin{tabular}{l|l} 
Characteristic & $\%$ \\
\hline Interaction with parents: \% reporting: & 77.5 \\
Serious conflict with family members & 60.5 \\
Parents showed little understanding of their needs & 63.5 \\
Parents did not spend enough time with them & 53.5 \\
Beaten by mother, father or both & 46.0 \\
Parents were very strict & 49.5 \\
Parents were strict about how children spent money & 39.0 \\
Parents were strict about their choice of friends &
\end{tabular}




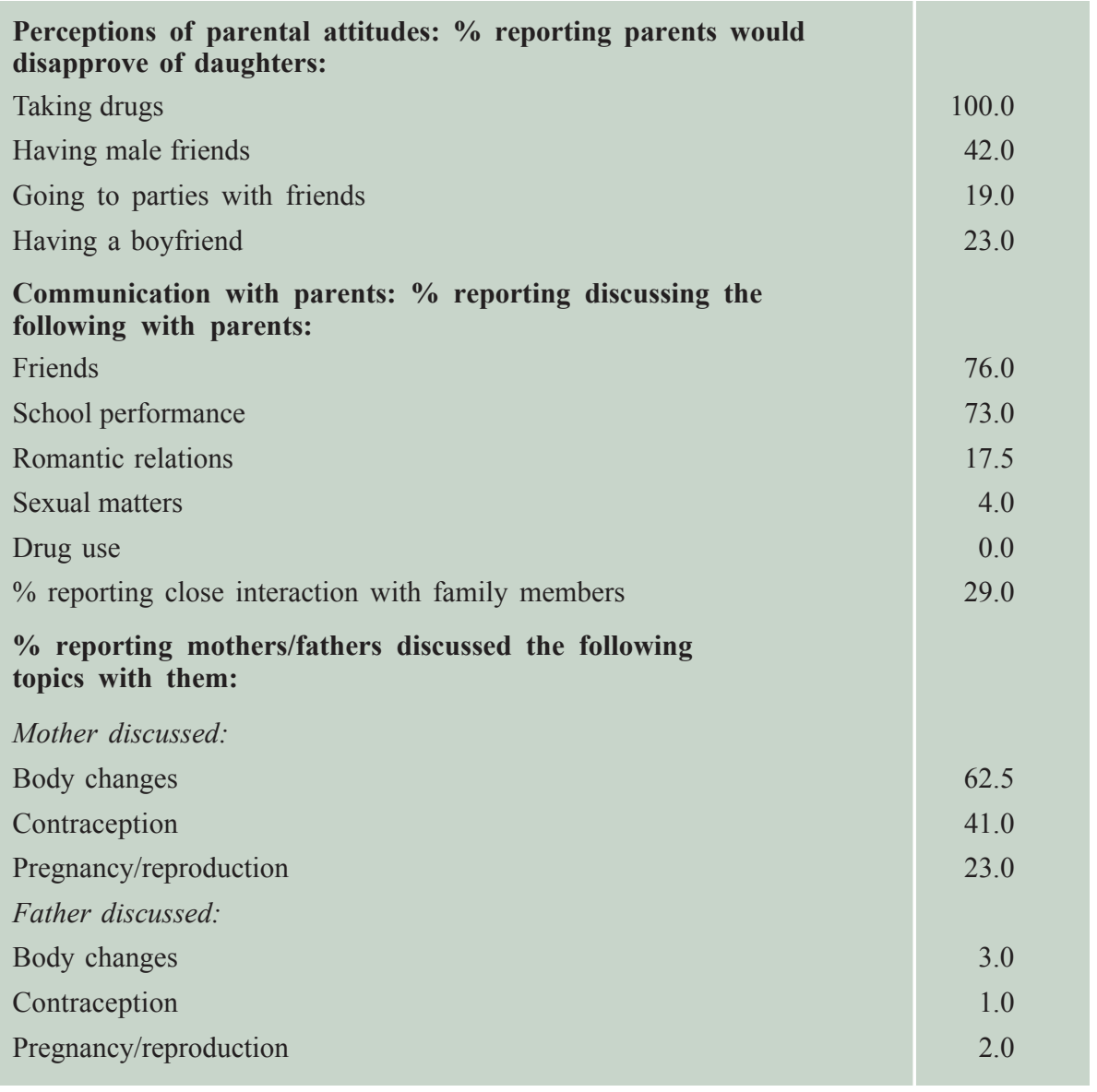

The survey also probed the nature of parent-child communication. Only a few respondents $(29 \%)$ reported close interaction with family members. There appeared to be more communication on non-sensitive topics as compared to sensitive ones. For example, three-fourths of respondents (76\%) had discussed school performance and friends with parents, but romantic relations, drug use or sexuality issues were discussed by far fewer $(0-18 \%)$. Fathers appeared to be more reticent than mothers in communicating with their daughters on all topics; while between one-fifth and three-fifths of all respondents reported that their mothers had talked with them about various matters including physical changes, contraception and sexual issues, fewer than five percent reported that their fathers had discussed these matters with them. 


\section{Experiences and patterns of drug use}

\section{Initiation of drug use}

For most respondents, drug use was initiated at an early age. As reported in Table 4, 43 percent of all respondents had initiated drug use by age 20 .

Of the 200 respondents, the majority of injecting drug users (83\%) reported that they had initially consumed specific drugs such as N 10, Spasmo-proxyvon or Lobain or chased heroin. ${ }^{3}$ Interestingly, and of concern, is that an alarming 17 percent $(\mathrm{N}=34)$ had initiated drug use by injecting Spasmo-proxyvon or heroin. Both qualitative and survey data suggest that there was a gradual progression from oral consumption/chasing to injecting drug use. Frequently, the shift to injecting drug use occurred because it was perceived to be less expensive (46\%) or because it was reported to give a better high than oral consumption of drugs and chasing (38\%) (not shown in tabular form).

While respondents reported several reasons for initiating drug use, the majority indicated that they had begun to use drugs as a result of peer pressure or the desire to overcome feelings of depression (Table 4). The following quotes corroborate this finding.

\section{I tried my hardest to make my boyfriend stop injecting drugs but I failed. I was so frustrated and angry that I too started taking drugs orally. Now, I inject with him. (22 years, female injecting drug user, Imphal East district)}

After three years of marriage, I was unable to conceive. I was having problems with my husband and in-laws. Though it was a love marriage, my husband wanted to remarry. I was heartbroken. I came back to my parents place. I was under so much tension that I started drinking heavily and gradually started "fixing" [injecting drugs] just to feel better. (26 years, female injecting drug user, Churachandpur district)

Other reasons for initiating drug use were for fun or out of curiosity. Some respondents said that they had been tricked into using drugs or, as the following quote shows, were introduced to drug use by their partners.

My husband and I went to Imphal with a friend of his who was a drug peddler. My husband started using drugs; I learned it [drug use] from him. (28 years, female injecting drug user, Imphal West district)

3 Chasing is inhaling the fumes of heroin/brown sugar using a thin sheet of paper. 
Table 4:

Initiation of drug use $(\mathrm{N}=\mathbf{2 0 0})$

\begin{tabular}{l|c}
\hline Characteristic & \% \\
\hline Initiated drug use by age 20: & 43.0 \\
\hline Method of drug use at initiation: & 83.0 \\
Oral/chased & 17.0 \\
Injected & \\
Reasons for initiating drug use*: & \\
\hline Peer/partner pressure & 45.0 \\
Peer pressure & 7.5 \\
Introduced by drug-using husband/boyfriend & \\
\hline $\begin{array}{l}\text { Depression } \\
\text { To overcome feelings of depression }\end{array}$ & 45.0 \\
To cope with separation from romantic partner & 3.0 \\
\hline Curiosity or fun & \\
Curious about the effect of drugs & 20.5 \\
For fun & 16.5 \\
Others & \\
Somebody tricked the respondent & 2.5 \\
\hline
\end{tabular}

${ }^{*}$ Multiple responses.

\section{Patterns of drug use}

Not surprisingly, almost all respondents (92\%) reported daily drug use (Table 5). The majority of respondents (46\%) reported injecting three times a day; however, 42 percent reported injecting at least four times a day.

Most respondents (88\%) noted that heroin was the primary drug injected in the last one month. At the same time, respondents reported injecting a number of other drugs as well. For example, nearly 15 percent reported that Spasmo-proxyvon was the main drug injected in the last one month; the use of raw opium was also reported, but by far fewer $(0.5 \%)$ (not shown in tabular form). Respondents noted that opium is cultivated in the interior villages where it is widely consumed, including by women, and that although expensive, is easily available in the study areas. The use of drugs at parties, during festivals and at picnics was common. The use of drugs among peers was also fairly widespread; for example, 35 percent of respondents said that they had at least one friend who sniffed drugs and 55 percent had at least one friend who chased drugs. Many more respondents had a least one friend who took drugs orally or injected drugs $(83 \%$ and $89 \%$, respectively) (not shown in tabular form). 
Findings show that drug use was expensive. Almost half the study respondents (46\%) reported that they spent Rs. 100-300 a day on drugs. Those who reported injecting drugs more than four times a day cited a daily expense of about Rs. 500 .

\section{Table 5:}

Patterns of drug use $(\mathrm{N}=\mathbf{2 0 0})$

\begin{tabular}{l|c} 
Characteristic & $\%$ \\
\hline Frequency of drug use: \% injecting drugs: & \\
Daily & 92.0 \\
Less than three times a day & 12.5 \\
Three times a day & 46.0 \\
Four times a day & 25.0 \\
More than four times a day & 16.5 \\
Daily expenditure on drugs: & \\
< Rs. 100 & 9.0 \\
Rs. $101-200$ & 24.0 \\
Rs. $201-300$ & 22.0 \\
Rs. $301-400$ & 19.5 \\
Rs. $401-500>$ & 9.0 \\
Rs. 501 & 16.5 \\
Type of drug ever used: \% reporting ever used the following: & \\
Drugs injected and used orally & \\
Heroin (No. 4) (chased and injected) & 93.5 \\
Spasmo-proxyvon (used orally and injected) & 59.0 \\
Raw opium (used orally and injected) & 15.0 \\
Drugs used orally & \\
Lobain & 73.5 \\
N 10 (Nitrosun 10) & 51.0 \\
Valium & 42.0 \\
Alprazolam & 26.0 \\
Phensydyl & 21.0 \\
Diazepam & 13.5 \\
Buprenorphine & 11.5 \\
Codeine & 7.5 \\
Relipin & 4.0 \\
Calmpose & 2.0 \\
\hline
\end{tabular}




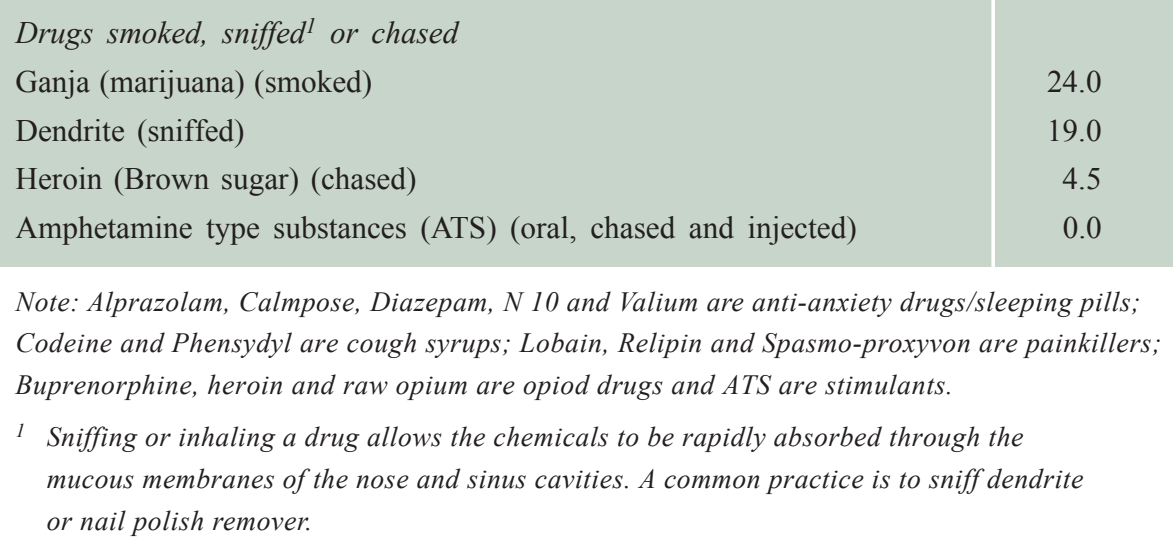

Note: Alprazolam, Calmpose, Diazepam, $N 10$ and Valium are anti-anxiety drugs/sleeping pills; Codeine and Phensydyl are cough syrups; Lobain, Relipin and Spasmo-proxyvon are painkillers; Buprenorphine, heroin and raw opium are opiod drugs and ATS are stimulants.

1 Sniffing or inhaling a drug allows the chemicals to be rapidly absorbed through the mucous membranes of the nose and sinus cavities. A common practice is to sniff dendrite or nail polish remover.

\section{Unsafe drug injecting practices}

Study findings show that drug injecting practices were risky (see Table 6). The vast majority of respondents $(82 \%)$ reported re-using needles and injecting equipment; of those who reused equipment, only 17 percent reported that they always washed re-used equipment, mainly using tap water or sometimes water from drains, rivers or ponds for cleaning (not shown in tabular form). Sharing of needles was almost universal; most respondents $(97 \%)$ reported that they had done so despite the fact that 86 percent were aware of sources of clean injecting materials and how to access NGOs that provide these services (not shown in tabular form). More than two-thirds of all respondents $(68 \%)$ mentioned that the main reason for sharing injecting equipment was the lack of a regular supply of clean equipment. There is some evidence of a shift towards safer practices. For example, of the women who reported accessing safe equipment and supplies $(\mathrm{N}=172), 73$ percent noted that they go sometimes or often to Drop in Centres (DIC) to access clean equipment, and 75 percent reported that NGO staff sometimes or often provide them with clean equipment.

During in-depth interviews, respondents indicated that the fear of police action leads them to seek isolated spaces, such as river banks, funeral places/cremation grounds and public toilets for drug use, and to disregard issues of safety and hygiene.

I can somehow hide the stuff [heroin] but not the needle and syringe. When the police are in our place [where she lives in Imphal West], I can't inject so I go to the river bank. I always find a syringe there because people [use them and] throw them near the river bank. I have to take my daily dose. I have shared [syringes] many times in the past. (30 years, female injecting drug user, Imphal West district) 
Table 6:

Drug injecting practices and reasons for re-using injecting equipment

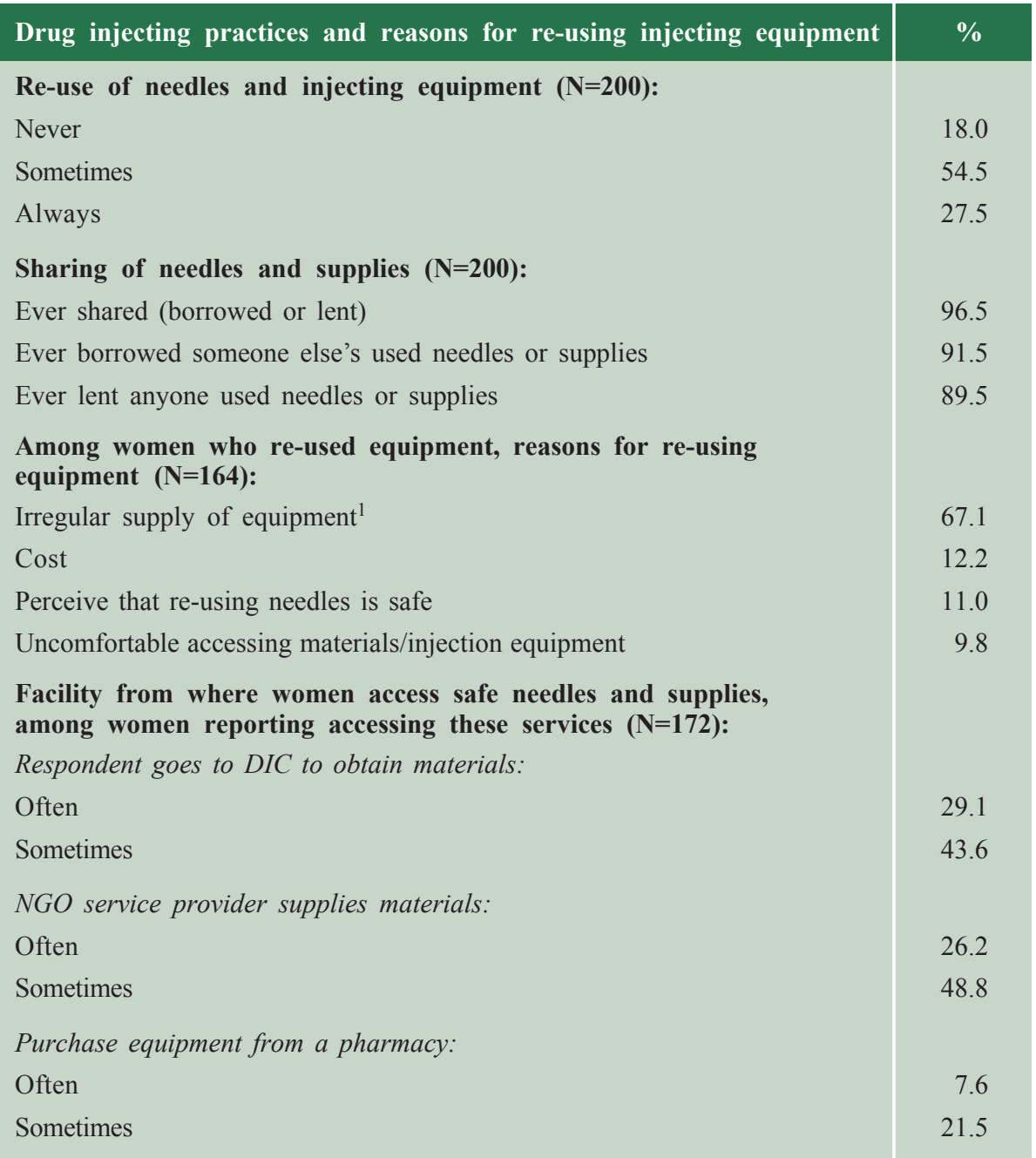

1 Sometimes outreach workers or peers may not supply clean injecting material, or injecting drug users may not be able to go to the DIC because of "bandhs" (a bandh is a general strike during which business activity and sometimes even traffic movement is forcibly prevented by the strikers), strikes and curfew in the area.

\section{Supporting the drug habit}

As noted, drug use is expensive, and respondents reported adopting a number of strategies to procure money for drugs. Almost all respondents (98\%) reported selling their personal or family belongings, one-third (33\%) reported selling drugs and 18 percent reported stealing money or valuables to support their habit (see Table 7). Narratives corroborate these findings. For example: 
I am afraid that one day my son and daughter will find out [that I inject drugs]. ... I even stole my daughter's gold ring because I was getting withdrawal symptoms. I cannot tell them that I have been injecting drugs for the past eight years. (32 years, female injecting drug user, Imphal West district)

More than half of all respondents (56\%) reported that they had engaged in sex work to obtain money to purchase drugs, and someone in $10(11 \%$ of all respondents) reported that they had engaged in sex in exchange for drugs.

\section{Table 7:}

Strategies adopted to support the drug habit $(\mathrm{N}=\mathbf{2 0 0})$

Strategies adopted

Respondents reporting that they had:

Sold personal/family belongings to buy drugs

Stolen money/valuables from others to buy drugs

Peddled drugs to buy drugs

Had sex to get money for drugs

Had sex in exchange for drugs

Had sex in exchange for gifts

\section{Table 8:}

Perceptions of the importance of parental, peer and societal reactions $(\mathrm{N}=\mathbf{2 0 0})$

\begin{tabular}{l|c} 
Perceptions & $\%$ \\
\hline Respondents' perceptions of the importance of: & \\
Parental reactions & 56.5 \\
Care a lot & 32.0 \\
Care somewhat & 11.5 \\
Don't care at all & \\
Peer reactions & 9.0 \\
Care a lot & 82.0 \\
Care somewhat & 9.0 \\
Don't care at all & \\
Societal reactions & 11.5 \\
Care a lot & 59.0 \\
Care somewhat & 29.5 \\
Don't care at all &
\end{tabular}




\section{Support mechanisms}

The study also explored the reactions of key family members to respondents' drug use. Most respondents (74\%) reported that family members were aware that they were injecting drugs (not shown in tabular form). However, families were not always supportive; of those whose families were aware of their drug habit $(\mathrm{N}=147), 61$ percent reported that their families had encouraged them to seek treatment and 23 percent said that they had been thrown out of their homes. One-third reported that their families had faced discrimination from the community due to their drug habit (35\%). Respondents noted the lack of family support in interviews as well. For example:

I was introduced to drugs by my husband. When I became totally dependent on drugs, he didn't want to share [heroin] with me as the costs were high. I started working in a shop as a helper to cover the cost [of purchasing drugs]. My mother-in-law came to know [about my habit] and after days of quarrels and humiliation, I was thrown out of the house. I don't have a permanent place to stay in Imphal. Most nights I spend at the shop where I work. My husband is a Central Government employee and he has told me not to tell anyone that I am his wife. I have three children. I miss them a lot but they hate me now. They don't even want to see me. (30 years, female injecting drug user, Imphal West district)

While the general belief is that drug users are indifferent to how people perceive them, the study findings suggest that respondents were extremely concerned about their reputation, particularly with regard to the opinion of parents, peers and to a lesser extent, society more generally (Table 8 ). 


\section{Sexual behaviour of injecting drug users}

\section{Sexual experiences with boyfriends}

The vast majority of respondents (92\%) were sexually active. Partners were by and large boyfriends. Ninety percent of respondents had at least one boyfriend, and all but one respondent reported having ever engaged in sex with a romantic partner (Table 9). Some boyfriends had eventually married the respondent.

Respondents reported multiple boyfriends, with 24 percent reporting four or more boyfriends. More than a quarter (27\%) reported sex with more than one romantic partner. Sexual relations were initiated early, with two in three of all respondents (74\%), reporting sexual relations with a boyfriend by age 20 . For the large minority of respondents - about one in three - sexual initiation with boyfriends was persuaded or forced. About two-fifths reported that either they or their boyfriends were already on drugs at the time of first sex. Among respondents reporting more than one boyfriend $(\mathrm{N}=136), 10$ percent reported they had been forced/persuaded to have sexual relations with their most recent romantic partner. Condom use was rare, with 20 percent reporting regular condom use with any boyfriend.

\section{Table 9:}

Sexual experiences with boyfriends

\section{Characteristics of sexual experiences}

Ever had a boyfriend $(\mathrm{N}=200)$

Number of boyfriends ( $\mathbf{N}=\mathbf{2 0 0})$ :

No boyfriend

One

Two

Three

Four or more

Sexual relations with boyfriend $(\mathrm{N}=180)$ : \% reporting sex with:

At least one boyfriend

First boyfriend

More than one boyfriend

Age at first sex with boyfriend $(\mathrm{N}=178)^{1}$ :

$\%$ reporting sex with a boyfriend by age 20

Consensuality of sexual experiences with boyfriend:

With first boyfriend $(N=91)$

Consensual 
Respondent forced/persuaded partner

Partner persuaded respondent

Partner forced respondent

With most recent boyfriend (for those reporting more

than one boyfriend) $(N=136)$

Consensual

Respondent forced/persuaded partner

Partner persuaded respondent

Partner forced respondent

Drug use status at initiation of sexual relationship with a boyfriend $(N=179)$

Respondent already on drugs

Partner already on drugs

$\%$ already on drugs and whose partner was also on drugs

\section{Condom use:}

Regular with first boyfriend ( $\mathrm{N}=91$ )

$\%$ reporting regular use with any boyfriend $(\mathrm{N}=179)$

${ }^{1}$ Age not known for one respondent.

\section{Sexual experiences with other partners}

Findings show that aside from sex with boyfriends, respondents also reported having engaged in sexual relations with other partners $(20 \%)$, mostly clients (not shown in tabular form). Indeed, more than half of all respondents reported that they had engaged in sex work for money to purchase drugs $(56 \%)$; some had exchanged sex more directly for drugs $(11 \%)$ or gifts $(5 \%)$ (see Table 10$)$.

Several female injecting drug users described how they migrated to Imphal for sex work during the summer months when the number of clients in their place of origin declined.

During festival time and on holidays like Holi, Christmas and Independence Day, we get many clients here [Churachandpur]. But in May and June there are not many clients, so we go to Imphal and stay with friends for some time. (27 years, female injecting drug user, Churachandpur district) 


\section{Table 10:}

Respondents' sexual experiences $(\mathrm{N}=\mathbf{2 0 0})$

\begin{tabular}{l|c}
\hline Sexual experiences & $\%$ \\
\hline \% reporting: & 89.5 \\
\hline Sex with a boyfriend & 55.5 \\
\hline Ever engaged in sex work for money & 13.0 \\
\hline Ever engaged in sex in exchange for drugs or gifts & 10.0 \\
\hline $\begin{array}{l}\text { Ever experienced forced sex (boyfriend or other partner) } \\
\text { Engaged in any of the above }\end{array}$ & 91.5 \\
\hline $\begin{array}{l}\text { Of those reporting any sexual experience (N=183), \% reporting regular } \\
\text { condom use in any sexual relationship (boyfriend or other partner) }\end{array}$ & 21.3
\end{tabular}

As can be seen from Table 10, some 10 percent of respondents reported being forced into sex either by a boyfriend or another partner. In-depth interviews corroborate respondents' experiences of forced sex:

The police personnel come here and pick up a girl of their choice and send her back the next morning. (30 years, female injecting drug user, Imphal West district)

Rape is very common among us, it is mentally very distressing... we usually avoid talking about it. (27 years, female injecting drug user, Imphal West district)

The majority of respondents $(76 \%)$ reported multiple sexual partners over the course of their lives (not shown in tabular form). The number of partners varied: 42 percent had experienced sex with more than 10 partners while 46 percent reported more than 100 partners (not shown in tabular form). Narratives corroborate the finding that respondents had engaged in sex with multiple partners. For example:

\section{I have lost count of how many people I have slept with. I have been doing this (sex work) for the past two years, and during the time of festivals I get around eight or nine clients a day. Otherwise, normally I have four to five clients a day. (19 years, female injecting drug user, Churachandpur district)}

As in sexual relationships with boyfriends, regular condom use during casual sex or sex work was rare. Indeed, only 21 percent of respondents reported regular condom use in any sexual relationship, with a boyfriend or any other partner (Table 10). Fewer than 10 percent of respondents who had engaged in sex work reported regular condom use; and none of those who admitted a forced experience reported condom use in that encounter (not shown in tabular form). 
Lack of condom use in sexual encounters was also highlighted in in-depth interviews:

Sometimes I don't use a condom with my clients because they give me extra money for it and I don't really care about others. I am already HIV-positive. If they want to, I don't have any problem not using a condom. (28 years, female injecting drug user, Churachandpur district)

While not explored in detail in this study, several respondents noted that they had become pregnant in the course of sex work, further underscoring the lack of condom use among this group. For example:

I didn't know that I was pregnant. When I realised, it was too late for me to have an abortion. Despite this, I still do sex work. Yesterday I had eight clients. (17 years, female injecting drug user, Imphal West district) 


\section{Health status and service seeking behaviour}

\section{Health status}

The survey assessed the general health status of female injecting drug users in the study. Respondents were asked if they had experienced any health problems in the three months preceding the survey. More than half of all respondents (69\%) had experienced a sexual or reproductive health problem; of these women, the majority $(55 \%)$ reported disturbed menstrual patterns (see Table 11). Some eight in 10 women who reported menstrual disorders had not menstruated for several months, and two in 10 had not menstruated for a year (not shown in tabular form).

Findings presented in Table 11 suggest that apart from menstrual irregularity, respondents had experienced other problems in the past three months that may be associated with their drug use or risky sexual behaviours. For example, many of the symptoms reported in Table 11 are suggestive of STI-almost two-fifths (38\%) experienced excessive vaginal

\section{Table 11:}

Health problems experienced in the three months prior to the survey $(\mathrm{N}=\mathbf{2 0 0})$

\begin{tabular}{l|c}
\hline Health problem experienced in the past three months & $\%$ \\
\hline Any sexual and reproductive health problem: & 69.0 \\
Irregular menstruation & 54.5 \\
White discharge & 38.0 \\
Burning while urinating & 18.0 \\
Pain in the genital area & 16.0 \\
\hline Any drug use related problem: & 21.0 \\
Weight loss & 16.0 \\
Abscess & 6.0 \\
\hline Drug overdose & 5.5 \\
Others: & 41.0 \\
Liver problems ${ }^{1}$ & 25.5 \\
Skin infection & 14.0 \\
\hline Tuberculosis & 8.5 \\
\hline \% reporting one or more of the above problems & 100.0
\end{tabular}

${ }^{1}$ Includes hepatitis $C$, enlargement of the liver and yellow eyes. 
discharge, and 16 percent and 18 percent, respectively, reported pain in the genital area and burning while passing urine. Also notable is the finding that significant minorities reported problems related to drug use, such as weight loss and abscess. Some 5 percent had experienced a drug overdose. Other problems, including skin infections, liver problems and tuberculosis, were reported by 41 percent of respondents.

\section{Service seeking behaviour}

Although all respondents had experienced one or more health problems in the three months preceding the survey (see Table 11), service seeking for these problems was far from universal. As seen in Table 12, respondents generally sought care for problems such as skin infection, liver problems and tuberculosis; fewer had visited a facility for drug related problems or sexual and reproductive health complaints. For example, among respondents who had experienced problems such as skin infections, liver problems and tuberculosis in the past three months $(\mathrm{N}=82), 83$ percent had sought care at a facility; in contrast, of those who had experienced a sexual and reproductive health problem in the past three months, including irregular menstruation, white discharge, burning while urinating and pain in the genital area $(\mathrm{N}=138)$, only half had sought care at a facility (51\%). Similarly, among those who had experienced a drug related problem, such as abscess, weight loss or overdose in the past three months $(\mathrm{N}=42)$, only 38 percent reported accessing care for these problems at a facility.

\section{Table 12:}

Injecting drug users' care seeking behaviour and satisfaction with quality of care received at facilities

\footnotetext{
Characteristic

Of the women who had experienced a health problem in the past three months, \% who sought care for the following: Drug related problems ${ }^{1}(\mathrm{~N}=42)$

Sexual and reproductive health problems ${ }^{2}(\mathrm{~N}=138)$

Of the women who had ever visited a health facility for the following problems, \% reporting satisfaction with care received: Any drug related problem ${ }^{4}(\mathrm{~N}=167)$

Any sexual and reproductive health problem ${ }^{2}(\mathrm{~N}=79)$

1 Includes abscess, weight loss and drug overdose.

2 Includes irregular menstruation, white discharge, burning while urinating and pain in the genital area.

3 Includes tuberculosis, skin infection and liver problems such as hepatitis $C$, enlargement of the liver and yellow eyes.

4 Includes abscess, weight loss, drug overdose and detoxification treatment. Respondents were not asked about quality of care received for other problems; i.e., tuberculosis, skin infection and liver problems.
} 
The majority of respondents who had visited a facility appeared to be satisfied with the services received (see Table 12). It is interesting to note that while fewer women reportedly accessed care for drug related problems as compared to those who accessed care for problems related to sexual and reproductive health (38\% vs $51 \%$ ), many more women were satisfied with the services received for drug related problems than for sexual and reproductive health related problems ( $93 \%$ vs $61 \%)$.

Women who reported dissatisfaction with services noted, during in-depth interviews, that providers tended to be unsupportive and the services provided at facilities were not confidential. As a result, they were reluctant to visit a facility or had concealed their drug use from providers when they visited a facility. The following quote reflects the uncaring and insensitive attitude of providers in a drug treatment centre:

When I fell sick a year ago, I approached X [a particular drug treatment centre] for treatment. They refused to admit me with my daughter. I don't know who my daughter's father is... there was no one to look after her. She is no more... I will never go for treatment. I am not interested. (26 years, female injecting drug user, Imphal West district)

Women also cited other constraints to accessing care such as the costs that would be incurred at the health facility, and inconveniently located facilities.

While the large majority $(87 \%)$ of respondents reported that they had tried to give up the drug habit-almost three-quarters (73\%) of these women had sought help for this from an NGO centre or detoxification centre-all respondents were unsuccessful in curtailing the habit (not shown in tabular form). Sustained contact with services was limited; indeed, many had relapsed back into drug use after only a few days, indicating injecting drug users' limited access to counselling facilities. The reasons for relapse appeared to be the same as the reasons for initiating drug use-association with drug using partners and peers, and feelings of depression.

As reported in settings elsewhere, key informants in Manipur also noted that few programmes in the state address female injecting drug users, and that female drug users are more reluctant to access services as compared to males. These views are reflected in the following quotes:

There are no national guidelines for female drug users. We have only recently realised the need to provide services to this group. But there are certain rules and formalities to be followed before starting a programme. (Key informant interview, state-level policy maker, Imphal West district)

I have more male patients [injecting drug users] coming to me. The male-female ratio is 4:1. (Key informant interview, STI service provider, Imphal West)

While working with female injecting drug users I have noticed that they face a lot of harassment from law enforcers and women's prohibition groups. May be this is the reason why they don't seek health services. They don't even want to consult our 
doctor in the DIC. They come only when the problem is very serious. (Focus group discussion, service providers at NGO facilities, Imphal East district)

The study also enquired into the priority needs of injecting drug users as perceived by the respondents themselves. Not unexpectedly, given that the use of services by respondents was limited, most injecting drug users $(60 \%)$ reported that counselling and support services were priority needs for this group (see Table 13). The need for other services, such as short-term detoxification centres, was also stressed. Several respondents

\section{Table 13:}

Priority needs of injecting drug users, as reported by respondents $(\mathrm{N}=\mathbf{2 0 0})$

\begin{tabular}{l|c}
\hline Priority needs of injecting drug users identified by respondents $^{\mathbf{1}}$ & $\mathbf{\%}$ \\
\hline Counselling and support & 60.0 \\
Detoxification centres & 44.0 \\
General health services & 29.0 \\
Job/loan after recovery/rehabilitation & 22.5 \\
Vocational training centres & 22.0 \\
Needle and syringe exchange programme & 12.5 \\
Sexual and reproductive health services & 10.5 \\
Support group post-recovery & 10.0 \\
Night shelter & 8.5 \\
Day care centre/recreational centre/DIC & 7.5 \\
IEC material & 0.5 \\
Don't know/No response & 1.0
\end{tabular}

${ }^{1}$ Multiple responses.

also noted the need for general health services, vocational training and economic support systems including micro-finance and employment opportunities, post-recovery. Fewer women reported the need for needle and syringe exchange programmes (NSEP), night shelters, day care for children, DICs, social support groups and Information Education and Communication (IEC) material. Surprisingly, only a few reported the need )for provision of sexual health services. 


\section{Factors underlying female injecting drug users' vulnerability to HIV}

Study findings indicate that female injecting drug users engage in high levels of risky drug use and unsafe sexual behaviours. Several factors appear to exacerbate their vulnerability to acquiring HIV infection, including limited self-perception of HIV risk, and limited in-depth awareness of safe sex and drug use practices. Traditional attitudes towards gender and sexuality further compromise their vulnerability.

\section{Limited self-perception of HIV risk}

As can be seen from Table 14, about two in three injecting drug users perceived that they were at risk of acquiring HIV. Of these $(\mathrm{N}=137)$, a third $(37 \%)$ reported that they were at risk because of unhygienic injecting drug use and a similar proportion (34\%) reported they were at risk because of risky sexual and drug use practices, including multiple partner sex, sex work, inconsistent use of condoms and sharing injecting equipment. Two-thirds of respondents (67\%) had undergone HIV testing at least once. The study did not ask them to divulge their HIV status.

\section{Table 14:}

Respondents' perception of risk and experience of HIV testing

\section{Characteristic}

Perception of risk $(\mathrm{N}=\mathbf{2 0 0})$ :

$\%$ reporting they perceive themselves to be at risk of acquiring HIV

Among women who perceived they were at risk of acquiring HIV $(N=137)$, \% reporting that:

Unhygienic drug use places them at risk

Sharing injecting equipment and unsafe sexual practices places them at risk

Experience of HIV testing $(\mathbf{N}=\mathbf{2 0 0})$ :

$\%$ reporting they have been tested at least once for HIV

\section{Limited in-depth awareness of safe sex and drug use behaviours}

The study assessed respondents' awareness of reproductive health matters. As seen in Table 15 , all respondents $(100 \%)$ had heard of HIV and the vast majority $(80-95 \%)$ were aware of the modes of HIV transmission. However, in-depth awareness of reproductive health matters was limited. While four-fifths had heard of STIs, far fewer (48\%) could identify three symptoms of infection, and only 47 percent had heard of hepatitis C. Likewise, few respondents reported awareness of issues related to pregnancy and methods of contraception. Only 53 percent of respondents were aware that a woman can 
get pregnant the first time she has sexual intercourse and two-thirds or fewer were aware of oral pills and withdrawal as methods of contraception. Of interest is the finding that almost all respondents (95-98\%) recognised the importance of premarital HIV testing for both young women and men (not shown in tabular form).

The study also explored respondents' awareness of the linkages between unsafe injecting drug use and infection, such as abscess, HIV and hepatitis C. Findings show that the vast majority of respondents were aware of the link between unsafe injecting drug practices and abscesses (92\%) and HIV (100\%) (Table 16). However, relatively few $(39 \%)$ were aware that sharing injecting equipment can lead to hepatitis C, although it is likely that there is a well-established HIV and hepatitis C co-infection epidemic among injecting drug users in Manipur, and that associated adverse health consequences have been identified.

Table 15:

Awareness of reproductive health matters and safe sex behaviours $(\mathrm{N}=\mathbf{2 0 0})$

\begin{tabular}{l|c} 
Awareness of select reproductive health matters & $\%$ \\
\hline Reproductive health awareness: & 100.0 \\
Heard about HIV/AIDS & 82.5 \\
Heard about STIs & 46.5 \\
Heard about hepatitis C & 47.5 \\
Can identify at least 3 symptoms of STIs ${ }^{1}$ & \\
Safe sex awareness and misperceptions: \% reporting that: & 95.0 \\
Hugging an HIV-positive person does not transmit HIV & 94.5 \\
Sharing food with an infected person does not transmit HIV & 93.5 \\
Regular condom use can reduce the risk of HIV & 92.0 \\
One cannot tell by looking at a person whether s/he is HIV-positive & 80.0 \\
One can reduce the risk of acquiring HIV by having just one partner & \\
Pregnancy and contraception related awareness: \% reporting: & 53.0 \\
A woman can get pregnant the first time she has sexual intercourse & 68.0 \\
Aware of the following methods of contraception: & 59.0 \\
Oral pills & \\
Withdrawal & \\
\hline & Respondents were asked the following question: "Can you describe any symptoms of infection \\
that people can get from sexual contact?" Responses included ulcer/sore on private parts, \\
genital discharge, itching in private parts, tenderness/pain in lower abdomen; warts/growths on \\
private parts, burning/pain on urination, or that an infected person can be asymptomatic.
\end{tabular}




\section{Table 16:}

Awareness of risky drug use practices $(\mathrm{N}=\mathbf{2 0 0})$

\begin{tabular}{l|r}
\hline Awareness of drug use practices & $\mathbf{\%}$ \\
\hline \% reporting that: & 100.0 \\
Sharing of needles/equipment can lead to HIV & 92.0 \\
Injecting can lead to abscess and other health complications & 39.0 \\
\hline Sharing of needles/equipment can lead to hepatitis C
\end{tabular}

\section{Traditional attitudes towards sexuality and gender roles}

The survey also inquired about respondents' attitudes to premarital and extra-marital sex and drug use. Findings, presented in Table 17, suggest a dissonance between female injecting drug users' attitudes and behaviours. Despite the fact that all respondents have used drugs and almost all have engaged in premarital and/or extra-marital sex, respondents reported relatively conservative attitudes about the acceptability of premarital sex. For example, a large proportion did not approve of premarital and extra-marital sex for young women. Attitudes to drug use, likewise, acknowledged that society looks down on drug users. Many held attitudes that reflect the gender double standards prevailing in society. For example, about half the respondents were of the view that a boy would not respect a girl who engages in sexual relations with him, and almost three-quarters felt that a girl should be a virgin at the time of marriage. Similarly, the majority of respondents believed that society looks down on female drug users and male drug users (98\% and $90 \%$, respectively).

\section{Table 17:}

Respondents' attitudes to sexuality and drug use ( $\mathrm{N}=\mathbf{2 0 0})$

\begin{tabular}{l|l}
\hline Attitudes & $\%$ \\
\hline Attitudes to sexual norms: & \\
$\%$ who agree that: & 51.0 \\
A boy will not respect a girl who is willing to have sex with him & \\
It is all right for girls and boys to have sex before marriage if they & 55.0 \\
use a contraceptive method to prevent pregnancy & 75.0 \\
A girl should remain a virgin until marriage & 6.5 \\
It is all right for a married woman to have extra-marital sex \\
Attitudes to drug use: \\
\% who agree that: \\
If a young man takes drugs, people will talk badly of him \\
If a young woman takes drugs, people will talk badly of her
\end{tabular}




\section{Summing up and recommendations}

\section{Summing up}

The findings of this study highlight the extent to which female injecting drug users are at dual risk of acquiring HIV, hepatitis C and STIs through unsafe drug use and risky sexual practices, and of transmitting the infection to the general population. As findings show, risky sexual behaviours were widespread: most respondents reported multiple partners, over half had engaged in sex work and condom use was sporadic in all relationships. Moreover, in-depth knowledge about STIs, including HIV, was limited. Although it is likely that there is a well-established HIV and hepatitis C co-infection epidemic among injecting drug users in Manipur, awareness of hepatitis $\mathrm{C}$ was poor.

As in the general population, the attitudes of most drug injecting women suggest that they disapproved of the very behaviours in which they engage, namely, drug use and premarital, extra-marital or commercial sex. Fear of disclosure and stigma led most drug injecting women to make significant efforts to conceal their risky behaviours from families in particular, and society in general. Finally, care seeking for drug-related problems and sexual health was far from universal; facilities for injecting drug users were largely oriented to males, and most females in the sample reported that services were not easily accessible or client-friendly, that providers were judgemental, and that they lacked the finances to seek care.

\section{Recommendations}

Findings suggest that female injecting drug users in Imphal require attention on various fronts. The finding that respondents lack in-depth awareness of safe and unsafe drug use and sexual practices as well as the location and availability of health services, highlights the need to build awareness among them about both safe sex and drug use practices. IEC materials need to be developed, for example, that address these information gaps about safe sex and drug use, simultaneously if possible. These materials need to be designed in consultation with female injecting drug users, using terminologies and visuals with which the group can identify and easily understand. These materials can be distributed to female injecting drug users in the course of outreach work.

Female injecting drug users are clearly a disempowered and highly vulnerable group; they are socially isolated, face stigma and have few realistic options. In this context, it is necessary to create a supportive environment that enables injecting drug users to discuss and address their needs more openly, that reduces the social isolation of drug using women and that makes families and the wider community aware of their role in ensuring the health of drug injecting women. Efforts to bring together and empower the community are essential. An effective strategy to achieve this may be through establishing peer-led interventions, which would be acceptable to female injecting drug users, and would provide both social support and health services in a trusting environment. At the 
same time, the economic needs of female injecting drug users must be addressed by way of efforts to build livelihood or vocational skills, offer work opportunities and raise awareness about their rights and available options.

As injecting drug users have themselves indicated, there is a critical need for the provision of services to this group. Services for both safe drug use and sexual health must be made available in a gender-sensitive environment, and health providers should be sensitised to the particular needs of female drug injectors. Moreover, providers should be oriented to be non-judgmental and supportive of injecting drug using clients, and at the same time ensure confidentiality of their services.

Injecting drug users also have counselling needs. The finding that several respondents had initiated drug use to overcome depression, and that several had relapsed into drug use as a result of depression, suggests that counselling services need to be made available that address the emotional and mental health needs of injecting drug users on a sustained basis.

Outreach services are needed to reach female injecting drug users who face numerous obstacles to seeking facility-based care. The most appropriate manner to achieve this is by training a core of female outreach workers - preferably from the community - to raise awareness of safe behaviours and of injecting drug users' right to access services, provide them field-level counselling and supplies, and motivate and refer those in need to seek facility-based services for drug treatment and infection.

Findings indicate that, as in settings elsewhere, facility-based services in Imphal are largely geared to male injecting drug users. Given that female drug users are a growing population, services are needed to address their needs and efforts are required to ensure that services provided are sensitive to the needs of injecting drug users. For example, counsellors and services must be sensitive to the fact that female injecting drug users may be more concerned about privacy and confidentiality than males, that women drug users are more likely to have faced exploitation and violence, and that females may be more isolated and less able to find the resources needed to access and comply with treatment. Moreover, female health service providers must be available in facilities for injecting drug users. In short, facilities must be restructured in ways that recognise the significant numbers of drug injecting women in Imphal and the obstacles they face in accessing care.

Convergence of drug-related services and sexual and reproductive health services is essential. Our study has emphasised the extent to which unhygienic injecting drug use is combined with multiple partner sex, and commercial and unprotected sex. Services must recognise and address these dual risks faced by female injecting drug users, and associated experiences such as unwanted pregnancy, abortion and the experience of gender-based violence. At the same time, services need to address the reality of female injecting drug users' lives and ensure that once they have received treatment, they are linked to income-generating opportunities, which would enable them to resist the vicious cycle of drug peddling and sex work and return to drug use.

The State AIDS policy, thus far, has not specifically acknowledged the significant number of female injecting drug users who reside in Manipur. Targeted intervention projects of MSACS, likewise, have not included special programmes for this group. It is essential 
that the situation and needs of female injecting drug users become a part of state programming. Interventions for this group should be designed to address their multiple needs and the range of obstacles they face in adopting safe drug use and sexual practices. Linkages also need to be established with other sectors, for example, the Social Welfare Department, government hospitals, NGOs and community-based organisations, to make these programmes more effective.

Findings also call for the generation of more research evidence that sheds light on the magnitude of female injecting drug users, their risk taking patterns, the obstacles they face in adopting safe behaviours or acquiring appropriate services, and the experiences of successful interventions for this group.

In conclusion, the study underscores the need for programmes in Manipur that recognise and address the vulnerabilities of drug injecting women and the multiples risks they face of acquiring HIV, and of transmitting infection to the general community. 


\section{References}

Allan, K. 1994. "Female drug abusers and the context of their HIV transmission risk behaviours," in The Context of HIV Risks Among Drug Users and Their Sexual Partners, ed. R.J. Battjes, Z. Sloboda and W.C. Grace. NIDA Research Monographs 143, pp. 48-63.

Amin, A. and D. Burrows. In press. Where sex work, drug injecting and HIV overlap: Practical issues for reducing vulnerability, risk and harm. Geneva: World Health Organization.

Anderson, A.F. and X. Hua. 1998. "Guangxi on the precipice: Drug abuse behaviour and the nascent spread of HIV in one Chinese region," International Journal of Offender Therapy and Comparative Criminology 42 (4): 369-375.

Devaney, M., G. Reid and S. Baldwin. 2006. Situational Analysis of Drug Issues and Responses in the Asia Pacific Region. Report prepared for the Australian National Council on Drugs Research Paper 12. A collaborative project conducted by the Burnet Institute's Centre for Harm Reduction and Turning Point Alcohol and Drug Centre, Melbourne.

Eicher, A.D., N. Crofts, S. Benjamin et al. 2000. "A certain fate: Spread of HIV among young injecting drug users in Manipur, North-East India,” AIDS Care 12 (4): 497-504.

Hunter, G.M. and A. Judd. 1998. "Women injecting drug users in London: The extent and nature of their contact with drug health services," Drug and Alcohol Review 17:267-276.

Kumar, S. 2000. Rapid Situation Assessment of Drug Use in Chennai. Chennai: UNESCO DAPPA and SHARAN.

Liu, W., Q.Y Zhu, F.Y. Chen et al. 2002. Drug use, sexual behaviours and HIV infection among women in Guangxi, China. Abstract MoPeC3348. XIV International AIDS Conference, Barcelona, 7-12 July.

Manipur State AIDS Control Society (MSACS). 2006. Epidemiological Analysis of HIV/ AIDS in Manipur. Manipur, India.

McEwan, R., A. McCallum and R. Madnock. 1992. "Sex and HIV infection: The role of alcohol," British Journal of Addiction 87: 577-584.

Murthy, P. 2002. Women and Drug Abuse: The Problem in India. New Delhi: United Nations Office on Drugs and Crime and Ministry of Social Justice and Empowerment, Government of India.

National AIDS Control Organisation (NACO). 2002. Sentinel Surveillance Report: 20002001. New Delhi: NACO, Ministry of Health and Family Welfare.

National AIDS Control Organisation (NACO). 2006. HIV/AIDS Epidemiological Surveillance and Estimation Report for the year 2005. New Delhi: NACO, Ministry of Health and Family Welfare April. 
Osimani, M.L. 2003. The challenge of implementation of preventive programs in a developing country: Experiences, situations and perspectives in Uruguay, Clinical Infectious Diseases 37: S422-S426.

Panda, S., A. Chatterjee, S.K. Bhattacharya et al. 2000. "Transmission of HIV from injecting drug users to their wives in India," International Journal of STD and AIDS 11 (7): 468-473.

Panda, S., L. Bijaya, S. Devi et al. 2001. "Interface between drug use and sex work in Manipur," National Medical Journal India14 (4): 209-211.

Registrar General of India (RGI). 2001. Primary Census Abstract, Total Population: Table $A-5$, Series 1. New Delhi: RGI.

Sahai Trust and Population Council. 2004a. Estimating the prevalence of HIV-infection and other STDs among injecting drug users and their sexual partners in Chennai: A crosssectional study. New Delhi: Population Council.

Sahai Trust and Population Council. 2004b. Formative Research leading to the development of an intervention to reduce the risk of sexual transmission of HIV and STIs among drug users and their female partners in Chennai, India. New Delhi: Population Council.

Sarkar, S., P. Mukherjee and A. Roy. 1991. "Descriptive epidemiology of intravenous heroin users a new risk group for transmission of HIV in India," Journal of Infection 23: 201-207.

Sharma, M., S. Panda, U. Singh et al. 2003. "Five years of needle syringe exchange in Manipur, India: Programme and contextual issues," International Journal of Drug Policy 14: 407-415.

Singh, H.D. 2001. Rapid Situation Assessment of Drug Use in Imphal. Report for UNESCO, DAPPA and SHARAN, Imphal.

Social Awareness Service Organization (SASO). 2004. Project activity report for facilitating and providing access to treatment, care and support to female IDUs (July to December 2004). Unpublished.

Strathdee, S., N. Galai, M. Safaiean et al. 2001. "Sex differences in risk factors for HIV seroconversion among injecting drug users: A 10 year perspective," Archives of Internal Medicine 161(10): 1281-1288.

United Nations Office on Drug Control and Crime (UNODC). 2007. World Drug Report, 2007. Vienna: UNODC, Vienna International Centre.

WHO/UNAIDS/UNODC. 2004. Advocacy guide: HIV/AIDS Prevention among Injecting Drug Users. Geneva. 


\section{Acknowledgments}

Several people provided valuable assistance during the course of this study. I would like to thank all the team members-Ishwarchandra for support during the course of the study, Ch Bangkim and Phillip Laishram who helped design the study tools and analyse the data, and Bobo Meitei, Nangboi and Shyamshree RK for data collection. Peers at the Care Foundation, CSD, ECHEMA, IAC, Mangaal, SASO, Sahara, SHALOM and Sneha Bhavan helped in identifying the study respondents.

I am grateful to the study respondents who generously gave their time to share their experiences. Members of the Ethical Committee-Thiyam Bharat Singh, Lecturer in Economics and North East India Representative for Amnesty International, India; Esther Chinnu Haokip, Representative, Manipur Unit, North East Network; N. Ibungochoubi Singh, Executive Director, Manipur Mail; Thiyam Rajkishore Singh, Advocate and Founder Member of ETAROI, an NGO working for women on legal issues; Irene Salam, Professor, Manipur University and Secretary, All Manipur Catholic Union; R.K. Tharakshana Devi, Executive Member, THANIL (Thangmeiband Apunba Nupi Lup) and member of the All Manipur Women's Association against Drug Abuse and Alcoholism; Leban Serto, Secretary, Dr. Alphina Memorial Foundation; and Jeevan Yambem, Secretary ECHEMA, an NGO working on women's issues - provided valuable guidance. I would also like to acknowledge the support provided by Gary Reid, Suresh Kumar and Samiran Panda during the course of the study.

I would like to thank Shireen Jejeebhoy, K.G. Santhya, Shveta Kalyanwala, Francis Xavier and Komal Saxena at the Population Council for their guidance throughout the study and on previous versions of this report. Deepika Ganju edited the report and I am grateful for her valuable inputs and careful attention to detail. I am grateful to Gary Reid and Sanghamitra Iyengar for reviewing the report and Sohini Roychowdhury for overseeing the production of this report. 
